\section{Situação regulatória internacional de agrotóxicos com uso autorizado no Brasil: potencial de danos sobre a saúde e impactos ambientais}

\section{International regulatory situation of pesticides authorized for use in Brazil: potential for damage to health and environmental impacts}

\section{Situación regulatoria internacional de pesticidas con uso autorizado en Brasil: potencial de daños sobre la salud e impactos ambientales}

Karen Friedrich 1,2

Gabriel Rodrigues da Silveira 1

Juliana Costa Amazonas 1

Aline do Monte Gurgel 3

Vicente Eduardo Soares de Almeida 4

Marcia Sarpa 2,5

doi: 10.1590/0102-311X00061820

\title{
Resumo
}

A legislação brasileira não prevê revisão periódica do registro dos agrotóxicos $e$, ainda hoje, são utilizados produtos proibidos em outros países. Partindo dos ingredientes ativos de agrotóxicos registrados no país, o presente estudo investigou a situação regulatória internacional nos países-membros da Organização para a Cooperação e Desenvolvimento Econômico (OCDE), da Comunidade Europeia e BRICS. Também se buscou relacionar os principais efeitos crônicos à saúde humana e ao meio ambiente dos ingredientes ativos de agrotóxicos mais comercializados no Brasil, em listas de classificação de potencial cancerígeno (Agência de Proteção Ambiental dos Estados Unidos - USEPA e Agência Internacional de Pesquisa em Câncer - IARC), desregulação endócrina e candidatos para substituição (estes dois últimos da Comunidade Europeia). Foram identificados 399 ingredientes ativos de agrotóxicos registrados no Brasil para uso agrícola, excluindo-se os microbiológicos e agentes biológicos de controle. Destes, não têm autorização 85,7\% na Islândia, 84,7\% na Noruega, 54,5\% na Suiça, 52,6\% na Índia, 45,6\% na Turquia, 44,4\% em Israel, 43,4\% na Nova Zelândia, 42,4\% no Japão, 41,5\% na Comunidade Europeia, 39,6\% no Canadá, 38,6\% na China, 35, 8\% no Chile, 31,6\% no México, 28,6\% na Austrália e 25,6\% nos Estados Unidos. Foram relacionados a danos à saúde e ao ambiente 120 ingredientes ativos de agrotóxicos. Considerando os ingredientes ativos de agrotóxicos para os quais estão disponíveis dados de comercialização no país, 67,2\% deste volume está associado a pelo menos um dano crônico grave avaliado neste estudo. Os resultados do presente estudo indicam a necessidade de promover a transparência das bases de dados internacionais, no que tange às motivações para as respectivas decisões regulatórias e os órgãos reguladores brasileiros reavaliarem o registro de produtos obsoletos, fortalecendo politicas públicas relacionadas à redução do uso de agrotóxicos.

Agroquímicos; Neoplasias; Medição de Risco

\author{
Correspondência \\ K. Friedrich \\ Centro de Estudos em Saúde do Trabalhador e Ecologia \\ Humana, Escola Nacional de Saúde Pública Sergio Arouca, \\ Fundação Oswaldo Cruz. \\ Rua Leopoldo Bulhões 1480, Rio de Janeiro, RJ \\ 21041-210, Brasil. \\ karenfriedrich@hotmail.com \\ 1 Escola Nacional de Saúde Pública Sergio Arouca, Fundação \\ Oswaldo Cruz, Rio de Janeiro, Brasil. \\ 2 Instituto Biomédico, Universidade Federal do Estado do Rio de \\ Janeiro, Rio de Janeiro, Brasil. \\ 3 Instituto Aggeu Magalhães, Fundação Oswaldo Cruz, Recife, \\ Brasil. \\ 4 Universidade de Trás-os-Montes e Alto Douro, Vila Real, \\ Portugal. \\ 5 Instituto Nacional de Câncer José Alencar Gomes da Silva, Rio \\ de Janeiro, Brasil.
}




\section{Introdução}

O registro dos agrotóxicos que permite o seu uso e consumo, comercialização, além de produção, importação e exportação no Brasil é concedido pelo Ministério do Meio Ambiente e Ministério da Agricultura, Pecuária e Abastecimento, após a autorização de três órgãos reguladores: a Agência Nacional de Vigilância Sanitária (Anvisa), do Ministério da Saúde; o Instituto Brasileiro do Meio Ambiente e dos Recursos Naturais Renováveis (Ibama) e o Ministério da Agricultura, Pecuária e Abastecimento. Estes são os órgãos que avaliam os potenciais impactos sobre a saúde, o meio ambiente e a eficácia agronômica, respectivamente 1,2 .

Neste contexto, alguns efeitos sobre a saúde humana, como mutação genética, efeitos sobre o sistema reprodutivo, teratogenicidade, distúrbios hormonais e câncer, são considerados proibitivos para fins de registro, conforme disposto na letra "c" e “d", \$6, Art. 3, da Lei no 7.082/1989 1. A observação desses efeitos leva ao banimento daqueles agrotóxicos em processo de revisão de registro e ao indeferimento de novos ingredientes ativos.

Apesar disso, não há previsão legal, no Brasil, de periodicidade mínima para a reavaliação de registro. O Decreto no 4.074/2002 2 recomenda que essa revisão poderia, em tese, ocorrer a qualquer tempo, orientada por alertas internacionais, novos estudos científicos ou denúncias realizadas por instituições de referência, nos termos do seu inciso VI, art. 2. No âmbito da Anvisa, a reavaliação toxicológica é realizada de acordo com os critérios dispostos na Resolução da Diretoria Colegiada - RDC no 221, de 28 de março de 2018 3 , porém a norma também não prevê periodicidade mínima ou prazo máximo para sua conclusão. Percebe-se, ainda, que, mesmo em casos de alertas internacionais, a limitação de recursos disponíveis nos órgãos ou as ações judiciais movidas por corporações vinculadas ao agronegócio, não raro, dificultam e atrasam tais revisões, agravando o quadro de exposição da população a esses produtos perigosos 4 .

Para além da fragilidade do atual quadro regulatório brasileiro, as recentes propostas de alteração da legislação 5 apontam para uma flexibilização, fato que tem preocupado instituições de pesquisa, entidades de defesa da ordem jurídica, dos interesses democráticos e organizações sociais, especialmente com a ampliação nacional da comercialização de produtos que não são utilizados em outros países ${ }^{6}$. Neste cenário, é possível que o Brasil se consolide como um grande mercado para produtos obsoletos, que podem causar danos às populações expostas e à biodiversidade ${ }^{7}$.

Considerando esses aspectos, o objetivo deste estudo foi identificar e analisar o perfil dos ingredientes ativos de agrotóxicos registrados no Brasil e o seu status regulatório internacional em paísesmembros da Organização para a Cooperação e Desenvolvimento Econômico (OCDE), da Comunidade Europeia, Índia e China, identificando potenciais danos à saúde e ao meio ambiente associados.

\section{Metodologia}

O estudo consiste em uma pesquisa documental. Foram identificados os ingredientes ativos de agrotóxicos autorizados no Brasil a partir da consulta da relação de monografias autorizadas, disponível no site da Anvisa. Destes, foram excluídos do estudo os produtos microbiológicos e os agentes biológicos de controle.

A partir das monografias da Anvisa, os ingredientes ativos de agrotóxicos foram identificados quanto aos seguintes aspectos: grupo químico, classificação de toxicidade aguda, indicação de uso e estado de aprovação para outros usos (não agrícola, domissanitário de venda livre ou venda especializada; uso em campanhas de saúde pública, uso em jardinagem amadora, aplicação como preservativo de madeira). Aqueles destinados exclusivamente a usos não agrícolas foram excluídos do estudo.

Para identificação da carcinogenicidade dos ingredientes ativos de agrotóxicos autorizados no Brasil, as listas de classificação da Agência Internacional de Pesquisa em Câncer da Organização Mundial da Saúde (IARC/OMS) 8 e da Agência de Proteção Ambiental Americana (USEPA) 9 foram consultadas. Também foram pesquisadas as listas da Comunidade Europeia sobre os agrotóxicos candidatos para substituição 10 e aqueles potencialmente desreguladores endócrinos 11 . 
Para a pesquisa, foram destacados os agrotóxicos com maior volume de comercialização no Brasil em 2017, tomando como base o relatório de comercialização disponível no site do Ibama (https:// www.ibama.gov.br/index.php).

As informações sobre registro foram coletadas para 35 dos 36 países-membros da OCDE (Austrália, Canadá, Chile, Estados Unidos, Islândia, Israel, Japão, México, Nova Zelândia, Noruega, Suíça, Turquia, Reino Unido e o bloco da Comunidade Europeia, que inclui 22 países-membros da OCDE) e dois países do bloco dos BRICS, Índia e China, cujas bases de dados estavam disponíveis no idioma inglês. O Reino Unido deixou de fazer parte da Comunidade Europeia durante a realização deste estudo, porém a fonte das informações sobre saúde e segurança são as mesmas da Comunidade Europeia até 31 de dezembro de 2020 e a apesar de a Coreia do Sul ser um país-membro da OCDE, seus dados não foram incluídos por causa da dificuldade de acesso aos ingredientes ativos de agrotóxicos autorizados no site oficial do país.

As informações referentes à situação de registro no Brasil e nos demais países foram coletadas nos sítios eletrônicos dos respectivos órgãos oficiais, no período de 15 de maio de 2017 até 31 de agosto de 2019: Autoridade Australiana de Pesticidas e Medicamentos Veterinários (Australian Pesticides and Veterinary Medicines Authority - https://portal.apvma.gov.au/pubcris;jsessionid=3WzzhEa PP5w4Pd19oL+xuTkv); Anvisa (http://portal.anvisa.gov.br/registros-e-autorizacoes/agrotoxicos/ produtos/monografia-de-agrotoxicos/autorizadas); Saúde Canadá (Health Canada - http://pr-rp. hc-sc.gc.ca/pi-ip/index-eng.php); Serviço Agrícola e Pecuário (Servicio Agrícola y Ganadero, Chile - http://www.sag.cl/ambitos-de-accion/evaluacion-y-autorizacion-de-plaguicidas/1367/registros); Banco de dados de Segurança Alimentar-Plantas-Pesticidas-Pesticidas (Food Safety-PlantsPesticides-Pesticides Database, Comunidade Europeia - http://ec.europa.eu/food/plant/pesticides/ eu-pesticides-database/public/?event=homepage\&language=EN); Agência Ambiental da Islândia (The Environmental Agency of Iceland - https://www.ust.is/english/chemicals/biocides/activesubstances/); Ministério da Agricultura e Bem-Estar dos Agricultores (Ministry of Agriculture \& Farmers Welfare, India - (http://ppqs.gov.in/sites/default/files/registeried_formulation_29.02.2020. pdf); Ministério da Agricultura e Desenvolvimento Rural (Ministry of Agriculture and Rural Development, Israel - (http://www.hadbara.moag.gov.il/hadbara/english/search/NoKotelForm.asp); Centro de Inspeção de Alimentos e Materiais Agrícolas (Food and Agricultural Materials Inspection Center, Japão - http://www.acis.famic.go.jp/eng/ailist/index.htm); Comissão Federal de Proteção contra Riscos Sanitários (Comisión Federal para la Protección contra Riesgos Sanitarios, México - http:// siipris03.cofepris.gob.mx/Resoluciones/Consultas/ConWebRegPlaguicida.asp); Autoridade Norueguesa de Segurança Alimentar (Norwegian Food Safety Authority - https://www.mattilsynet.no/ plantevernmidler/godk.asp?sortering=virkestoff\&preparat=Alle\&sprak=In\%20English); Ministério das Indústrias Primárias, governo da Nova Zelândia (Ministry for Primary Industries - Manatu Ahu Matua https://eatsafe.nzfsa.govt.nz/web/public/acvm-register); Escritório Federal de Agricultura - Diretório de Produtos de Proteção de Plantas, Suíça (Bundesamt fur Landwirtschaft - Pflanzenschutzmittelverzeichnis - https://www.psm.admin.ch/de/wirkstoffe); Ministério da Alimentação, Agricultura e Pecuária, Turquia (Ministry of Food, Agriculture and Livestock - https://bku.tarim.gov. tr/BKURuhsat/Index). Já as informações da situação de registro dos Estados Unidos foram obtidas do site Rede de Ação de Pesticidas (Pesticide Action Network - PAN - Pesticide Database - http://www. pesticideinfo.org/Search_Chemicals.jsp\#ChemSearch), e as da China foram obtidas de documento publicado pela Organização das Nações Unidas para a Alimentação e a Agricultura (FAO) 12.

Em todas as bases de dados utilizadas, pesquisou-se a situação de registro de cada um dos ingredientes ativos de agrotóxicos permitidos no Brasil. Destacaram-se aqueles não autorizados na Comunidade Europeia e/ou em pelo menos três países-membros da OCDE. Tal destaque se fundamenta em uma das propostas de alteração da Lei no 7.802/1989, que autoriza a concessão de registro temporário no Brasil de ingredientes ativos de agrotóxicos aprovados em pelo menos três países-membros da OCDE, caso os órgãos reguladores não avaliem os dossiês de registro em 24 meses 5 .

A pesquisa buscou ainda identificar as razões técnicas de proibição na Europa para os ingredientes ativos de agrotóxicos cujos dados de comercialização para o ano de 2017 foram disponibilizados e publicados através de relatórios no site do Ibama, aprofundando o aspecto qualitativo do estudo. 


\section{Resultados}

\section{Perfil geral dos ingredientes ativos de agrotóxicos autorizados no Brasil}

No site da Anvisa, foram identificadas 450 monografias autorizadas de ingredientes ativos de agrotóxicos químicos, bioquímicos, semioquímicos, microbiológicos e agentes biológicos de controle autorizados no Brasil.

Para este estudo, consideramos apenas os ingredientes ativos de agrotóxicos classificados como químicos e semioquímicos, perfazendo um total de 401 ingredientes ativos de agrotóxicos, incluindo nesta lista o paraquate, que tem sua proibição no Brasil programada para 22 de setembro de 2020.

Foram identificados metabólitos dentro de algumas monografias, que são reconhecidos como ingredientes ativos de produtos comercializados no Brasil ou em outros países e, por isso, foram tratados individualmente, totalizando 458 ingredientes ativos de agrotóxicos. Destes, observou-se que 318 são de uso exclusivo agrícola, 59 são de uso exclusivamente não agrícola, 78 de ambos e três são autorizados exclusivamente para exportação (os herbicidas aclonifem, bromoxinil e diflufenicam). Como as bases de dados internacionais estudadas referem-se a produtos autorizados para a agricultura, foram excluídos aqueles de uso exclusivo não agrícola, totalizando 399 ingredientes ativos de agrotóxicos pesquisados.

Dentre os 78 ingredientes ativos de agrotóxicos que são permitidos para uso agrícola e não agrícola, 54 são permitidos para uso domissanitário, sendo 24 autorizados para venda livre e 13 para venda restrita especializada. O uso em campanhas de saúde pública é permitido para 27 ingredientes ativos de agrotóxicos. Um total de 25 ingredientes ativos de agrotóxicos tem autorização para jardinagem amadora, e oito para uso como preservantes de madeira, além da permissão para uso agrícola.

\section{Efeitos crônicos sobre a saúde e impactos ambientais}

Do total de 399 ingredientes ativos de agrotóxicos considerados neste estudo, 116 foram diretamente relacionados a efeitos crônicos sobre a saúde humana ou ao meio ambiente. Na lista da USEPA de avaliação do potencial cancerígeno 7, 52 ingredientes ativos de agrotóxicos foram classificados como "prováveis" ou "possíveis" cancerígenos para seres humanos, sendo que, destes, quatro apresentavam ressalvas quanto ao nível de exposição ou ao tipo de efeito. Apresentavam evidências sugestivas do potencial cancerígeno para seres humanos 16 ingredientes ativos de agrotóxicos, enquanto outros oito apresentavam evidências sugestivas de carcinogenicidade, porém sem informações suficientes para avaliar o potencial cancerígeno para seres humanos (Quadro 1). A nomenclatura das diferentes classes de potencial cancerígeno da USEPA foi atualizada, por essa razão existem agrotóxicos com potenciais semelhantes de causar câncer, mas alocados em diferentes classes.

A IARC analisou 36 ingredientes ativos de agrotóxicos e, desse total, 15 têm uso autorizado no Brasil, sendo a diazinona, o glifosato e a malationa classificados como prováveis cancerígenos (grupo 2A) e clorotanolil e 2,4-D como possíveis cancerígenos (grupo 2B) (Quadro 1).

Dentre os ingredientes ativos de agrotóxicos classificados quanto à desregulação endócrina, 17 receberam classificações com potencial para seres humanos ou vida selvagem, sendo: categoria 1 - evidência de desregulação endócrina em estudos in vivo; categoria 2 - evidência de desregulação endócrina em estudos in vitro; categoria 3 - sem evidências de desregulação endócrina ou sem dados disponíveis (Quadro 1). Ressalta-se que alguns ingredientes ativos de agrotóxicos ficaram simultaneamente em mais de uma categoria (alacloro, atrazina, 2,4-D e malationa), de modo que cinco ficaram na categoria 1 (quatro para humanos e um para vida selvagem) e 15 na categoria 2 (nove para humanos e seis para vida selvagem) (Quadro 1). Na lista dos 77 agrotóxicos candidatos a serem substituídos da Comunidade Europeia, 68\% estão autorizados no Brasil. 


\section{Quadro 1}

Agrotóxicos autorizados no Brasil e incluídos em listas relacionadas aos impactos sobre a saúde humana e meio ambiente.

\begin{tabular}{|c|c|}
\hline CLASSIFICAÇÃO & COMPOSTO \\
\hline \multicolumn{2}{|c|}{ Agência de Proteção Ambiental Americana (USEPA) - potencial cancerígeno } \\
\hline $\begin{array}{l}\text { Grupo B - provável cancerígeno para seres } \\
\text { humanos }\end{array}$ & $\begin{array}{l}\text { Daminozida (1991), diurom (2004), etridiazol, (terrazole) (1999), hidróxido de fentina (1990), } \\
\text { mancozebe (1999), metiram (1999), procimidona (1991), propargito (1992), tiodicarbe (1996) }\end{array}$ \\
\hline $\begin{array}{l}\text { Provavelmente carcinogênico para seres } \\
\text { humanos }\end{array}$ & $\begin{array}{l}\text { Bentiavalicarbe isopropílico (2005), carbaril (2002), clorotalonil (1997), cresoxim-metílico (1999), } \\
\text { diclofope-metílico (2000), epoxiconazol (2001), espirodiclofeno (2004), hexitiazoxi (2009), imazalil } \\
\text { (1999), iprodiona (1998), iprovalicarbe (2002), isoxaflutol (1997), metam-sódico (2009), oxadiazona } \\
\text { (2001), oxifluorfem (2010), pimetrozina (1999), piraflufem-etílico (2002), pirimicarbe (2005), } \\
\text { propinebe (2013), tiacloprido (2012), tiofanato-metílico (1999) }\end{array}$ \\
\hline $\begin{array}{l}\text { Provavelmente carcinogênico para seres } \\
\text { humanos: com exposição a altas doses } \\
\text { e prolongadas; Provavelmente não é } \\
\text { carcinogênico para seres humanos em } \\
\text { doses que não causam citotoxicidade e } \\
\text { hiperplasia celular regenerativa }\end{array}$ & Captana (2004) \\
\hline $\begin{array}{l}\text { Provavelmente carcinogênico para seres } \\
\text { humanos: em altas doses; Provavelmente } \\
\text { não é carcinogênico para seres humanos } \\
\text { em baixas doses }\end{array}$ & Alacloro (1997), lactofem (2006), tiabendazol (2002) \\
\hline $\begin{array}{l}\text { Grupo C - possível cancerígeno para seres } \\
\text { humanos }\end{array}$ & $\begin{array}{l}\text { Acefato (1985), alfa-cipermetrina (2012), asulam (2001), bifentrina (2003), bromacila (1993), } \\
\text { carbendazim (1989), cipermetrina (1988), dimetenamida (1995), dimetoato (2002), fipronil (1995), } \\
\text { linurom (2001), metidationa (1988), pendimetalina (1992), propiconazol (1992), tebuconazol (1993), } \\
\text { triadimefom (1996), triadimenol (1988), trifluralina (1986), zeta-cipermetrina (1988) }\end{array}$ \\
\hline $\begin{array}{l}\text { Evidência sugestiva de potencial } \\
\text { carcinogênico }\end{array}$ & $\begin{array}{c}\text { Acetocloro (2007), amitraz (2006), benzovindiflupir (solatenol) (2014), ciflumetofem (2013), } \\
\text { clodinafope-propargil (2006), diclorana (2006), difenoconazol (2007), ditianona (2006), etiprole } \\
\text { (2010), fenoxaprope-etilico (2013), fluensulfona (2014), ortossulfamurom (2006), picoxistrobina } \\
\text { (2011), sulfoxaflor (2012), tembotriona (2007), tiazopir (2007) }\end{array}$ \\
\hline $\begin{array}{l}\text { Evidência sugestiva de carcinogenicidade, } \\
\text { mas não o suficiente para avaliar o } \\
\text { potencial de carcinogenicidade em } \\
\text { humanos }\end{array}$ & $\begin{array}{l}\text { Bioaletrina (2003), boscalida (2002), buprofezina (2000), clorfenapir (2003), fluazinam (2001), } \\
\text { fosmete (1999), malationa (2000), penoxsulam (2011) }\end{array}$ \\
\hline \multicolumn{2}{|c|}{ Agência Internacional de Pesquisa em Câncer (IARC) - potencial cancerígeno } \\
\hline Grupo $2 \mathrm{~A}$ - provável cancerígeno & Diazinona (2017), glifosato (2017), malationa (2017) \\
\hline Grupo 2B - possível cancerígeno & 2,4-D (2018), clorotalonil (1999) \\
\hline \multicolumn{2}{|r|}{ Comunidade Europeia - potencial desregulação endócrina } \\
\hline $\begin{array}{l}\text { Categoria } 1 \text { - evidência de desregulação } \\
\text { em pelo menos uma espécie utilizando } \\
\text { animais intactos }\end{array}$ & Humanos: acetocloro, alacloro, atrazina, tiram; vida selvagem: acetato de fentina \\
\hline $\begin{array}{l}\text { Categoria } 2 \text { - evidência in vitro de atividade } \\
\text { biológica relacionada a desregulação } \\
\text { endócrina }\end{array}$ & $\begin{array}{l}\text { Humanos: 2,4-d, brometo de metila, dimetoato, diurom, iprodiona, malationa, propanil, simazina, } \\
\text { triadimefom; vida selvagem: 2,4-d, alacloro, atrazina, carbendazim, diazinona, e malationa }\end{array}$ \\
\hline \multicolumn{2}{|c|}{ Comunidade Europeia - ingredientes ativos de agrotóxicos candidatos para substituição } \\
\hline $\begin{array}{l}\text { Bifentrina, bromuconazol, carbendazim, cip } \\
\text { epoxiconazol, esfenvalerato, etofenproxi, et } \\
\text { fluquinconazol, glufosinato, haloxifope-p, in } \\
\text { metribuzim, metsulfurom-metílico, miclobu } \\
\text { paclobutrazol, pendimetalina, pirimicarbe, p }\end{array}$ & $\begin{array}{l}\text { conazol, ciprodinil, diclofope, difenoconazol, diflufenicam, dimetoato, dimoxistrobina, diquate, } \\
\text { profós, etoxazol, famoxadona, fenamifós, fipronil, fludioxonil, flumioxazina, fluopicolida, } \\
\text { zamoxi, lambda-cialotrina, linurom, lufenurom, metam, metconazol, metilciclopropeno, metomil, } \\
\text { nil, nicossulfurom, oxadiargil, oxadiazona, oxicloreto de cobre, óxido de fembutatina, oxifluorfem, } \\
\text { ofoxidim, propiconazol, quizalofope-p, sulfato de cobre, tebuconazol, tepraloxidim, tiacloprido }\end{array}$ \\
\hline
\end{tabular}


Do total de ingredientes ativos de agrotóxicos estudados e autorizados no Brasil, 3,5\% (n = 14) (abamectina, cletodim, dicamba, dimetomorfe, glifosato, imidacloprido, lambda-cialotrina, MCPA, metribuzim, metalaxil-M, propamocarbe, tebuconazol, tiacloprido, tiofanato-metílico) têm aprovação em todos os países-membros da OCDE. Quando incluídos os países estudados do BRICS, esse número diminui para 12, pois se observou que cletodim e dicamba não possuem autorização de uso na Índia.

Um total de 17 ingredientes ativos de agrotóxicos não tem autorização em todos os países-membros da OCDE, e 16 ingredientes ativos de agrotóxicos também não têm na China e na Índia. Observou-se que $81 \%$ dos agrotóxicos autorizados no Brasil não têm permissão de uso em pelo menos três países da OCDE, e 31\% não tem aprovação na China e na Índia.

$O$ percentual de ingredientes ativos de agrotóxicos não autorizados ou não encontrados nas bases de dados dos países para autorização de produtos foi de: Islândia (85,7\%), Noruega (84,7\%), Suíça (54,5\%), Índia (52,6\%), Turquia (45,6\%), Israel (44,4\%), Nova Zelândia (43,4\%), Japão (42,4\%), Comunidade Europeia (41,5\%), Canadá (39,6\%), China (38,6\%), Chile (35,8\%), México (31,6\%), Austrália $(28,6 \%)$ e Estados Unidos (25,6\%) (Figura 1). Dentre os agrotóxicos com dados de comercialização disponíveis no Brasil, o percentual de não autorizações foi: Noruega (77\%), Islândia (75\%), Suíça (44\%), Turquia (38\%) e Comunidade Europeia (35\%).

\section{Autorização internacional dos ingredientes ativos de agrotóxicos mais comercializados no Brasil e associação com os efeitos crônicos à saúde e ao meio ambiente}

Em termos de volumes totais de comercialização de ingredientes ativos de agrotóxicos no Brasil, 539.944,95 toneladas foram comercializadas em 2017. Destas, 9,7\% não foram especificadas

\section{Figura 1}

Autorização, em países-membros da Organização para a Cooperação e Desenvolvimento Econômico (OCDE), China e Índia, dos ingredientes ativos de agrotóxicos permitidos no Brasil.

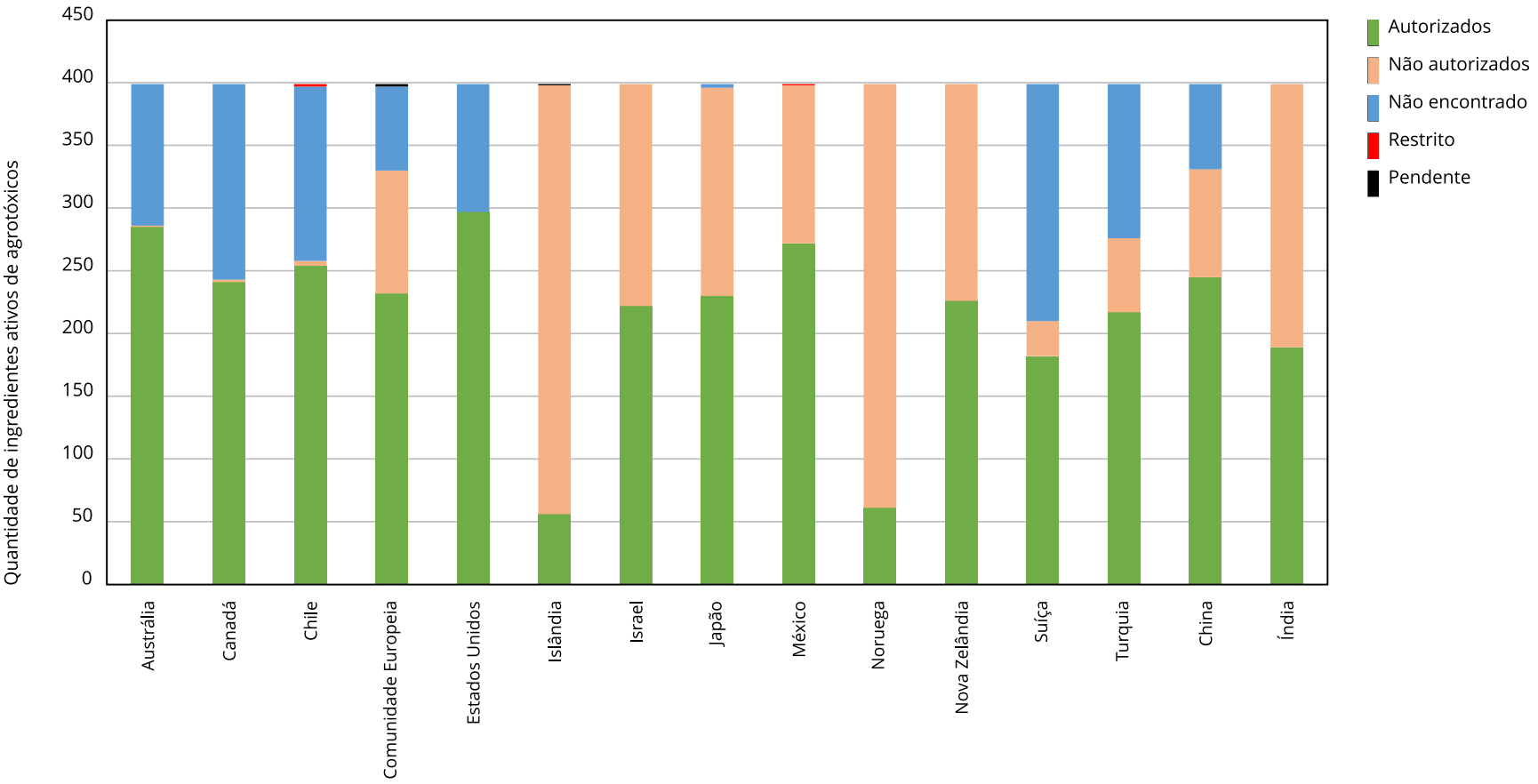


às substâncias que não possuem ao menos três empresas detentoras do registro para preservar o sigilo comercial.

Dentre os 79 ingredientes ativos de agrotóxicos que apareceram no relatório de comercialização de 2017, 14 tiveram diminuição de vendas no período citado. Considerando-se os 20 ingredientes ativos de agrotóxicos com maior volume de comercialização, 18 apresentaram aumento no período, destacando-se o tetraconazol, que aumentou mais de 22 vezes (Tabela 1).

Considerando todos os ingredientes ativos de agrotóxicos com dados de comercialização divulgados pelo Ibama, $67,2 \%$ do volume comercializado no ano de 2017 apresentam ao menos um critério relacionado a danos à saúde humana e ao meio ambiente constante nas listas que identificam efeitos sobre a saúde humana ou a vida selvagem, i.e., lista de potencial cancerígeno segundo IARC (possível ou provável cancerígeno) ou a USEPA (reconhecido, possível e provável cancerígeno), de desreguladores endócrinos e de candidatos para substituição da Europa (Quadro 1). A Tabela 1 apresenta os dados dos 20 ingredientes ativos de agrotóxicos com maior volume de comercialização, excluindo os óleos mineral e vegetal, representando $75 \%$ do volume total comercializado em 2017; 11 deles se enquadram em pelo menos um critério que evidencia potencial dano crônico segundo as listas consultadas.

Ainda em relação aos ingredientes ativos de agrotóxicos com dados de comercialização, 54\% não estão autorizados em pelo menos três países da OCDE, e 34\% não são autorizados na Comunidade Europeia. Quanto aos países do BRICS pesquisados neste estudo, 15 ingredientes ativos de agrotóxicos não têm autorização de uso na Índia (cletodim, fluazinam, flumetralina, imazalil, imazaquim, lactofem, mesotriona, MSMA [metano arseniato ácido monossodico], nicossulfurom, picloram, procimidona, simazina, sulfluramida, tebutiurom, triclopir-butilico), e cinco não podem ser usados na China (ciproconazol, flumetralina, MSMA, sulfentrazona e tebutiurom). Dentre os 20 mais comercializados, 11 (55\%) não estão autorizados em pelo menos três países da OCDE, e cinco, (25\%) na Comunidade Europeia (Tabela 2).

Dentre os ingredientes ativos de agrotóxicos sem autorização em pelo menos três países da OCDE e/ou na Comunidade Europeia, o volume total comercializado foi de 129.727,67 toneladas, correspondendo a $24 \%$ do total de ingredientes ativos de agrotóxicos vendido em 2017. No Brasil, 16,4\% do volume total de vendas correspondem a produtos não autorizados na Comunidade Europeia (Tabelas 1 e 2).

\section{Critérios para não autorização dos ingredientes ativos de agrotóxicos na Comunidade Europeia}

O Quadro 2 apresenta os dados de efeitos sobre a saúde e o meio ambiente para 19 dentre os 27 ingredientes ativos de agrotóxicos com dados de comercialização no Brasil e não autorizados na Comunidade Europeia. Não foram incluídos no Quadro 2: quatro ingredientes ativos de agrotóxicos sobre os quais não se tinha informação (clorimuron-etílico, sulfentrazona, sulfluramida e triclopir-butotílico); dois ingredientes ativos de agrotóxicos (diafentiurom e MSMA) que tinham como justificativa de proibição o Regulamento no 2.076/2002 da Comunidade Europeia por não atenderem a normativa vigente (Diretiva no 91/414), incluindo a necessidade de comprovação da inexistência de alternativas menos prejudiciais ou a necessidade de complementações de estudos; e dois ingredientes ativos de agrotóxicos (imazetapir e novalurom) para os quais outras regulações sobre a aprovação de ingredientes ativos de agrotóxicos específicos foram mencionadas. Merece destaque a sulfluramida, que tem como produtos de degradação o perfluorooctano sulfonato (PFOS), incluído no Anexo B (restrição) da Convenção de Estocolmo 13.

Os relatórios de conclusão dos processos de avaliação do registro na Comunidade Europeia de 11 ingredientes ativos de agrotóxicos mencionavam efeitos danosos sobre seres humanos e meio ambiente. Apresentaram associação a efeitos tóxicos críticos 15 ingredientes ativos de agrotóxicos, segundo a Diretiva da Europa no 1.272/2008, que implementou os critérios do Sistema Globalmente Harmonizado (GHS). Observou-se ainda que 12 ingredientes ativos de agrotóxicos apresentavam indicações de danos à saúde humana ou ao meio ambiente nas listas de efeitos crônicos consultadas (USEPA, IARC, candidatos para substituição na Europa e potenciais desreguladores endócrinos). 
Tabela 1

Indicações de uso agrícola e não agrícola dos 20 ingredientes ativos de agrotóxicos autorizados no Brasil com maior volume de comercialização em 2017 e seus aspectos relacionados à saúde humana.

\begin{tabular}{|c|c|c|c|c|c|c|c|c|c|c|c|c|c|c|c|}
\hline \multirow{2}{*}{$\begin{array}{l}\text { Ingredientes } \\
\text { ativos }\end{array}$} & \multirow{2}{*}{$\begin{array}{c}\text { Vendas em } \\
2017(\%)\end{array}$} & \multirow{2}{*}{$\begin{array}{c}\text { Variação } \\
\text { de vendas } \\
\text { entre 2009- } \\
2017(\%)\end{array}$} & \multirow{2}{*}{$\begin{array}{c}\text { Uso } \\
\text { agrícola }\end{array}$} & \multirow{2}{*}{$\begin{array}{c}\text { Outros } \\
\text { usos não } \\
\text { agrícolas * }\end{array}$} & \multirow[t]{2}{*}{ UD } & \multirow[t]{2}{*}{ VL } & \multirow[t]{2}{*}{ VE } & \multirow[t]{2}{*}{ CSP } & \multirow[t]{2}{*}{ JA } & \multirow[t]{2}{*}{ PM } & \multicolumn{5}{|c|}{ Listas de efeitos sobre a saúde } \\
\hline & & & & & & & & & & & USEPA & IARC & CFS & Desend H & Desend VS \\
\hline Glifosato & $173.150,75$ & 47,13 & $\mathrm{H}$ & $S$ & $\mathrm{~S}$ & $\mathrm{~N}$ & $\mathrm{~N}$ & $\mathrm{~N}$ & $\mathrm{~S}$ & $\mathrm{~N}$ & Não provável & $2 \mathrm{~A}$ & $\mathrm{NI}$ & $\mathrm{NI}$ & $\mathrm{NI}$ \\
\hline $2,4-D$ & $57.389,35$ & 381,20 & $\mathrm{H}$ & $\mathrm{S}$ & $\mathrm{N}$ & $\mathrm{N}$ & $\mathrm{N}$ & $\mathrm{N}$ & $\mathrm{N}$ & $\mathrm{N}$ & $\begin{array}{c}\text { Grupo D: não } \\
\text { classificável }\end{array}$ & $2 \mathrm{~B}$ & $\mathrm{NI}$ & 2 & 2 \\
\hline Mancozebe & $30.815,09$ & 804,82 & A, FG & $\mathrm{N}$ & $\mathrm{N}$ & $\mathrm{N}$ & $\mathrm{N}$ & $\mathrm{N}$ & $\mathrm{N}$ & $\mathrm{N}$ & $\begin{array}{c}\text { Grupo B: } \\
\text { provável } \\
\text { cancerígeno }\end{array}$ & $\mathrm{NI}$ & $\mathrm{NI}$ & $\mathrm{NI}$ & $\mathrm{NI}$ \\
\hline Acefato & $27.057,66$ & 421,16 & $A, 1$ & $\mathrm{~N}$ & $\mathrm{~N}$ & $\mathrm{~N}$ & $\mathrm{~N}$ & $\mathrm{~N}$ & $\mathrm{~N}$ & $\mathrm{~N}$ & $\begin{array}{c}\text { Grupo C } \\
\text { possível } \\
\text { cancerígeno }\end{array}$ & $\mathrm{NI}$ & $\mathrm{NI}$ & $\mathrm{NI}$ & $\mathrm{NI}$ \\
\hline Atrazina & $24.730,90$ & 191,76 & $\mathrm{H}$ & $\mathrm{S}$ & $\mathrm{N}$ & $\mathrm{N}$ & $\mathrm{N}$ & $\mathrm{N}$ & $\mathrm{N}$ & $\mathrm{N}$ & Não provável & 3 & $\mathrm{NI}$ & 1 & 2 \\
\hline Paraquate ** & $11.756,39$ & 581,33 & $\mathrm{H}$ & $\mathrm{N}$ & $\mathrm{N}$ & $\mathrm{N}$ & $\mathrm{N}$ & $\mathrm{N}$ & $\mathrm{N}$ & $\mathrm{N}$ & $\begin{array}{l}\text { Grupo E: Não } \\
\text { cancerígeno }\end{array}$ & $\mathrm{NI}$ & $\mathrm{NI}$ & $\mathrm{NI}$ & $\mathrm{NI}$ \\
\hline Imidacloprido & $9.364,57$ & 646,57 & I & $\mathrm{N}$ & $\mathrm{S}$ & $\mathrm{S}$ & $\mathrm{S}$ & $\mathrm{S}$ & $\mathrm{S}$ & $\mathrm{N}$ & $\begin{array}{l}\text { Grupo E: não } \\
\text { cancerígeno }\end{array}$ & $\mathrm{NI}$ & $\mathrm{NI}$ & $\mathrm{NI}$ & $\mathrm{NI}$ \\
\hline $\begin{array}{l}\text { Oxicloreto de } \\
\text { cobre }\end{array}$ & $7.443,62$ & 136,17 & $\mathrm{FG} ; \mathrm{B}$ & $\mathrm{N}$ & $\mathrm{N}$ & $\mathrm{N}$ & $\mathrm{N}$ & $\mathrm{N}$ & $\mathrm{N}$ & $\mathrm{N}$ & $\begin{array}{c}\text { Grupo D: não } \\
\text { classificável }\end{array}$ & $\mathrm{NI}$ & $\mathrm{S}$ & 3 & 3 \\
\hline Enxofre & $7.392,44$ & $-35,75$ & $A, F G$ & $\mathrm{~N}$ & $\mathrm{~N}$ & $\mathrm{~N}$ & $\mathrm{~N}$ & $\mathrm{~N}$ & $\mathrm{~N}$ & $\mathrm{~N}$ & $\mathrm{NI}$ & $\mathrm{NI}$ & $\mathrm{NI}$ & $\mathrm{NI}$ & $\mathrm{NI}$ \\
\hline Diurom & $6.999,47$ & 237,25 & $\mathrm{H}$ & $\mathrm{S}$ & $\mathrm{N}$ & $\mathrm{N}$ & $\mathrm{N}$ & $\mathrm{N}$ & $\mathrm{N}$ & $\mathrm{N}$ & $\begin{array}{c}\text { Provável } \\
\text { cancerígeno }\end{array}$ & $\mathrm{NI}$ & $\mathrm{NI}$ & 2 & 3 \\
\hline Clorpirifós & $6.471,19$ & 120,88 & A, FM, I & $\mathrm{N}$ & $\mathrm{S}$ & $\mathrm{S}$ & $\mathrm{N}$ & $\mathrm{N}$ & $\mathrm{N}$ & $\mathrm{S}$ & $\begin{array}{l}\text { Grupo E: não } \\
\text { cancerígeno }\end{array}$ & $\mathrm{NI}$ & $\mathrm{NI}$ & $\mathrm{NI}$ & $\mathrm{NI}$ \\
\hline Malationa & $6.094,65$ & 476,24 & $A, I$ & $\mathrm{~N}$ & $\mathrm{~S}$ & $\mathrm{~S}$ & $\mathrm{~S}$ & $\mathrm{~S}$ & $\mathrm{~S}$ & $\mathrm{~N}$ & $\begin{array}{l}\text { Sugestiva } \\
\text { mas não } \\
\text { suficiente }\end{array}$ & $2 \mathrm{~A}$ & $\mathrm{NI}$ & 2 & 2 \\
\hline Clorotalonil & $5.771,99$ & 193,78 & FG & $\mathrm{N}$ & $\mathrm{N}$ & $\mathrm{N}$ & $\mathrm{N}$ & $\mathrm{N}$ & $\mathrm{N}$ & $\mathrm{N}$ & $\begin{array}{c}\text { Provável } \\
\text { cancerígeno }\end{array}$ & $2 B$ & $\mathrm{NI}$ & $\mathrm{NI}$ & $\mathrm{NI}$ \\
\hline Clomazona & $4.559,90$ & 71,47 & $\mathrm{H}$ & $\mathrm{N}$ & $\mathrm{N}$ & $\mathrm{N}$ & $\mathrm{N}$ & $\mathrm{N}$ & $\mathrm{N}$ & $\mathrm{N}$ & Não provável & $\mathrm{NI}$ & $\mathrm{NI}$ & $\mathrm{NI}$ & $\mathrm{NI}$ \\
\hline Tetraconazol & $4.477,19$ & 2237,39 & $\mathrm{FG}$ & $\mathrm{N}$ & $N$ & $\mathrm{~N}$ & $\mathrm{~N}$ & $\mathrm{~N}$ & $\mathrm{~N}$ & $\mathrm{~N}$ & Não provável & $\mathrm{NI}$ & $\mathrm{NI}$ & $\mathrm{NI}$ & $\mathrm{NI}$ \\
\hline Tebutiurom & $4.092,41$ & 344,21 & $\mathrm{H}$ & $\mathrm{S}$ & $\mathrm{N}$ & $\mathrm{N}$ & $\mathrm{N}$ & $\mathrm{N}$ & $\mathrm{N}$ & $\mathrm{N}$ & $\begin{array}{c}\text { Grupo D: não } \\
\text { classificável }\end{array}$ & $\mathrm{NI}$ & $\mathrm{NI}$ & $\mathrm{NI}$ & $\mathrm{NI}$ \\
\hline Metomil & $3.766,44$ & 895,83 & $A, I$ & $\mathrm{~N}$ & $\mathrm{~S}$ & $\mathrm{~S}$ & $\mathrm{~S}$ & $\mathrm{~S}$ & $\mathrm{~N}$ & $\mathrm{~N}$ & $\begin{array}{l}\text { Grupo E: não } \\
\text { cancerígeno }\end{array}$ & $\mathrm{NI}$ & $\mathrm{S}$ & $\mathrm{NI}$ & $\mathrm{NI}$ \\
\hline Carbendazim & $3.748,26$ & $-42,78$ & FG & $\mathrm{N}$ & $\mathrm{N}$ & $\mathrm{N}$ & $\mathrm{N}$ & $\mathrm{N}$ & $\mathrm{N}$ & $\mathrm{S}$ & $\begin{array}{c}\text { Grupo C: } \\
\text { possível } \\
\text { cancerígeno }\end{array}$ & $\mathrm{NI}$ & $\mathrm{S}$ & 2 & 3 \\
\hline Cipermetrina & $3.570,28$ & 14,49 & FM, I & $\mathrm{N}$ & $\mathrm{S}$ & $\mathrm{S}$ & $\mathrm{S}$ & $\mathrm{S}$ & $\mathrm{N}$ & $\mathrm{S}$ & $\begin{array}{c}\text { Grupo C: } \\
\text { possível } \\
\text { cancerígeno }\end{array}$ & $\mathrm{NI}$ & $\mathrm{NI}$ & $\mathrm{NI}$ & $\mathrm{NI}$ \\
\hline Picloram & $3.127,41$ & 368,84 & $\mathrm{H}$ & $\mathrm{S}$ & $\mathrm{N}$ & $\mathrm{N}$ & $\mathrm{N}$ & $\mathrm{N}$ & $\mathrm{N}$ & $\mathrm{N}$ & $\begin{array}{l}\text { Grupo E: não } \\
\text { cancerígeno }\end{array}$ & 3 & $\mathrm{NI}$ & $\mathrm{NI}$ & $\mathrm{NI}$ \\
\hline
\end{tabular}

CFS: candidatos para substituição na Europa; Classes de uso - H: herbicida; I: inseticida; A: acaricida; FM: formicida; B: bactericida; FG: fungicida. CSP: campanhas de saúde pública; Desend H: desregulação endócrina para seres humanos; Desend VS: desregulação endócrina para vida selvagem; IARC: Agência Internacional de Pesquisa em Câncer da Organização Mundial da Saúde; JA: jardinagem amadora; PM: preservante de madeira; N: não; NI: não informado; S: sim; UD: uso domissanitário; USEPA: Agência de Proteção Ambiental Americana; VE: venda especializada; VL: venda livre.

* Uso em margens de rodovias, ferrovias e rede elétrica e em hidrelétricas;

** Será proibido em setembro de 2020. 
Tabela 2

Autorização internacional dos 20 ingredientes ativos de agrotóxicos com maior volume de comercialização em 2017, no Brasil.

\begin{tabular}{|c|c|c|c|c|c|c|c|c|c|c|c|c|c|c|c|}
\hline $\begin{array}{l}\text { Ingredientes } \\
\text { ativos }\end{array}$ & $\begin{array}{l}\text { Aus- } \\
\text { trália }\end{array}$ & $\begin{array}{l}\text { Cana- } \\
\text { dá }\end{array}$ & Chile & China & Índia & Israel & Japão & México & $\begin{array}{c}\text { Nova } \\
\text { Zelân- } \\
\text { dia }\end{array}$ & $\begin{array}{l}\text { Esta- } \\
\text { dos Uni- } \\
\text { dos }\end{array}$ & $\begin{array}{c}\text { Comu- } \\
\text { nidade } \\
\text { Euro } \\
\text { peia }\end{array}$ & $\begin{array}{l}\text { Islân- } \\
\text { dia }\end{array}$ & $\begin{array}{l}\text { Noru- } \\
\text { ega }\end{array}$ & $\begin{array}{l}\text { Tur- } \\
\text { quia }\end{array}$ & Suíça \\
\hline Glifosato & S & S & S & S & $\mathrm{S}$ & s & S & S & S & s & S & $P$ & s & S & S \\
\hline 2,4-D & S & S & S & S & $\mathrm{S}$ & S & S & S & S & S & S & NA & NA & S & S \\
\hline Mancozebe & S & S & S & S & $S$ & S & S & S & S & S & $\mathrm{S}$ & NA & $\mathrm{s}$ & S & S \\
\hline Atrazina * & S & S & S & S & $\mathrm{S}$ & $\mathrm{s}$ & $\mathrm{S}$ & $\mathrm{S}$ & $\mathrm{S}$ & s & NA & NA & NA & NA & NA \\
\hline Acefato * & S & $\mathrm{S}$ & S & S & $\mathrm{S}$ & NA & S & S & S & s & NA & NA & NA & NA & NA \\
\hline Paraquate * & S & NA & $\mathrm{R}$ & S & $\mathrm{S}$ & $\mathrm{s}$ & S & S & S & $\mathrm{s}$ & NA & NA & NA & NA & NA \\
\hline Imidacloprido & S & S & S & S & S & s & S & S & S & S & S & $\mathrm{S}$ & $\mathrm{S}$ & $\mathrm{S}$ & $\mathrm{S}$ \\
\hline $\begin{array}{l}\text { Oxicloreto de } \\
\text { cobre }\end{array}$ & S & $S$ & S & S & S & S & S & S & S & S & S & NA & NA & S & S \\
\hline Enxofre & S & $S$ & S & S & S & s & S & S & S & S & S & NA & NA & S & S \\
\hline Diurom & S & $S$ & S & S & $\mathrm{S}$ & s & S & S & S & S & s & NA & NA & S & S \\
\hline Clorpirifós & S & S & S & S & $\mathrm{S}$ & S & S & S & S & S & S & NA & NA & S & S \\
\hline Malationa * & s & S & S & s & S & s & s & S & S & s & S & NA & NA & S & NA \\
\hline Clorotalonil & S & S & S & S & $\mathrm{S}$ & S & S & S & S & S & S & NA & NA & S & $\mathrm{S}$ \\
\hline Clomazona & S & S & S & S & $\mathrm{S}$ & s & NA & s & $\mathrm{S}$ & s & s & $\mathrm{S}$ & s & S & $\mathrm{S}$ \\
\hline Tetraconazol * & S & S & S & $\mathrm{S}$ & $\mathrm{S}$ & $\mathrm{S}$ & $\mathrm{S}$ & S & NA & s & $\mathrm{S}$ & NA & NA & $\mathrm{S}$ & NA \\
\hline Tebutiurom * & S & S & S & NA & NA & NA & S & S & NA & $\mathrm{s}$ & NA & NA & NA & NA & NA \\
\hline Metomil & S & S & S & $\mathrm{S}$ & $\mathrm{S}$ & $\mathrm{S}$ & $\mathrm{S}$ & S & $\mathrm{S}$ & S & $\mathrm{S}$ & NA & NA & $\mathrm{S}$ & $\mathrm{S}$ \\
\hline Carbendazim * & S & S & S & S & s & s & NA & S & S & S & NA & NA & NA & NA & NA \\
\hline Cipermetrina & S & S & S & S & $\mathrm{S}$ & S & $\mathrm{S}$ & S & S & S & $\mathrm{S}$ & $\mathrm{S}$ & NA & $\mathrm{S}$ & $\mathrm{S}$ \\
\hline Picloram * & S & S & S & S & NA & S & NA & S & S & S & S & NA & NA & $\mathrm{S}$ & $\mathrm{S}$ \\
\hline
\end{tabular}

NA: não autorizado; P: pendente, mas com autorização temporária de uso; R: uso restrito; S: sim (autorizado).

* Ingredientes ativos de agrotóxicos proibidos em pelo menos três países da Organização para a Cooperação e Desenvolvimento Econômico.

\section{Discussão}

O presente estudo aponta, de maneira inédita, que aproximadamente $80 \%$ dos agrotóxicos autorizados no Brasil não têm permissão de uso em pelo menos três países da OCDE, incluindo países que têm na agricultura uma importante atividade econômica. Na Austrália, que possui $40 \%$ de seu território em condições agrícolas similares, não foram encontrados registros de 114 ingredientes ativos de agrotóxicos permitidos no território brasileiro. Embora Brasil e Índia possuam condições edafoclimáticas relativamente próximas, mais de 50\% dos agrotóxicos que têm registro no primeiro país não são permitidos no segundo. Também foi evidenciado que a relação de ingredientes ativos de agrotóxicos autorizados no Brasil inclui exemplos com reconhecida toxicidade sobre a saúde humana e o ambiente.

É importante salientar que, mesmo para os produtos autorizados no Brasil e em outros países, nestes as condições de uso e medidas de prevenção podem ser mais rígidas, diminuindo os danos causados 14,15. Dentre elas, destaca-se o uso permitido para poucas culturas com restrição de manuseio a trabalhadores treinados, como é o caso do glifosato na Europa ${ }^{16}$. Ademais, no Brasil, medidas que condicionam a segurança do uso de agrotóxicos não têm sido eficazes por diversas razões, como longas distâncias entre as propriedades e locais de venda ou descarte inadequado de embalagens e dificuldade no acesso a informações sobre uso e potenciais danos 17 .

A agricultura brasileira, além do uso de grandes volumes de agrotóxicos, também cultiva, de forma extensiva, lavouras transgênicas resistentes a herbicidas como o glifosato, 2,4-D e dicamba, resultan- 


\section{Quadro 2}

Ingredientes ativos de agrotóxicos com dados de comercialização no Brasil, mas não autorizados na Europa, e os danos ambientais e à saúde humana associados aos ingredientes ativos de agrotóxicos nas bases da Europa, Agência de Proteção Ambiental Americana (USEPA) e Agência Internacional de Pesquisa em Câncer da Organização Mundial da Saúde (IARC/OMS).

\begin{tabular}{|c|c|c|c|}
\hline Ingredientes ativos & $\begin{array}{l}\text { Conclusão relatório final de } \\
\text { proibição do registro da Europa }\end{array}$ & $\begin{array}{l}\text { Principais danos segundo } \\
\text { critério classificação - Diretiva } \\
\text { no } 1.272 / 2008\end{array}$ & $\begin{array}{c}\text { Efeitos relatados nas bases de } \\
\text { dados de efeitos à saúde e ao } \\
\text { meio ambiente }\end{array}$ \\
\hline Acefato & $\begin{array}{l}\text { Toxicidade aguda consumidores } \\
\text { Danos organismos não alvo: } \\
\text { artrópodes, pássaros, mamíferos e } \\
\text { animais aquáticos }\end{array}$ & Efeitos tóxicos se ingerido & $\begin{array}{c}\text { Possível cancerígeno para seres } \\
\text { humanos }\end{array}$ \\
\hline Ametrina & Sem informação & $\begin{array}{l}\text { Tóxico vida aquática (agudo e } \\
\text { crônico) }\end{array}$ & $\begin{array}{c}\text { Evidências cancerígeno para seres } \\
\text { humanos }\end{array}$ \\
\hline Atrazina & $\begin{array}{l}\text { Estudos insuficientes de } \\
\text { monitoramento e recuperação de } \\
\text { águas subterrâneas contaminadas }\end{array}$ & $\begin{array}{l}\text { Sensibilização dérmica, alergia, } \\
\text { tóxico exposição repetida, tóxico } \\
\text { vida aquática (agudo e crônico) }\end{array}$ & $\begin{array}{c}\text { Desregulação endócrina para seres } \\
\text { humanos e vida selvagem }\end{array}$ \\
\hline Brometo de Metila & $\begin{array}{l}\text { Estudos insuficientes impactos na } \\
\text { saúde humana e ambiental e risco } \\
\text { do trabalhador }\end{array}$ & Sem informação & $\begin{array}{c}\text { Desregulação endócrina para seres } \\
\text { humanos }\end{array}$ \\
\hline Carbendazim & Sem informação & $\begin{array}{c}\text { Tóxico vida aquática (agudo e } \\
\text { crônico). Mutágeno 1B }\end{array}$ & $\begin{array}{c}\text { Desregulação endócrina vida } \\
\text { selvagem, potencial carcinógeno } \\
\text { humano }\end{array}$ \\
\hline Dicloreto de Paraquate & Sem informação & $\begin{array}{l}\text { Fatal se inalado, irritante ocular } \\
\text { e dérmico, tóxico vida aquática } \\
\text { (agudo e crônico) }\end{array}$ & Sem informação \\
\hline Fenoxaprope-p-etílico & Sem informação & Sem informação & $\begin{array}{c}\text { Evidências cancerígeno para seres } \\
\text { humanos }\end{array}$ \\
\hline Fipronil & $\begin{array}{l}\text { Estudos insuficientes de impactos } \\
\text { ambientais (polinizadores). Danos } \\
\text { sobre colônias de abelhas }\end{array}$ & $\begin{array}{l}\text { Tóxico vida aquática (agudo e } \\
\text { crônico) }\end{array}$ & $\begin{array}{c}\text { Possível cancerígeno para seres } \\
\text { humanos, candidatos para } \\
\text { substituição na Europa }\end{array}$ \\
\hline Glufosinato - Sal de Amônio & Sem informação & $\begin{array}{l}\text { Potencial de toxicidade } \\
\text { reprodutiva para seres humanos }\end{array}$ & sem informação \\
\hline Hexazinona & Sem informação & $\begin{array}{c}\text { Efeitos imediatos e tardios vida } \\
\text { aquática, tóxico se ingerido, } \\
\text { irritante ocular }\end{array}$ & Sem informação \\
\hline Lactofem & Sem informação & Sem informação & $\begin{array}{c}\text { Provável cancerígeno para seres } \\
\text { humanos }\end{array}$ \\
\hline Permetrina & $\begin{array}{l}\text { Ecotoxicidade ecossistemas } \\
\text { aquáticos }\end{array}$ & $\begin{array}{l}\text { Efeitos imediatos e tardios vida } \\
\text { aquática }\end{array}$ & Sem informação \\
\hline Procimidona & $\begin{array}{l}\text { Estudos insuficientes sobre } \\
\text { desregulação endócrina }\end{array}$ & Potencial carcinogênico humano & Sem informação \\
\hline Propanil & $\begin{array}{c}\text { Estudos insuficientes sobre } \\
\text { impurezas, impactos ambientais e } \\
\text { efeitos consumidores. Transporte } \\
\text { longas distâncias pelo ar; elevado } \\
\text { risco para pássaros, mamíferos, } \\
\text { organismos aquáticos, artrópodes } \\
\text { não alvo }\end{array}$ & $\begin{array}{c}\text { Desregulação endócrina para } \\
\text { seres humanos, evidências } \\
\text { de carcinogenicidade para } \\
\text { humanos }\end{array}$ & Sem informação \\
\hline
\end{tabular}

(continua) 


\begin{tabular}{|c|c|c|c|}
\hline Ingredientes ativos & $\begin{array}{l}\text { Conclusão relatório final de } \\
\text { proibição do registro da Europa }\end{array}$ & $\begin{array}{c}\text { Principais danos segundo } \\
\text { critério classificação - Diretiva } \\
\text { no } 1.272 / 2008\end{array}$ & $\begin{array}{c}\text { Efeitos relatados nas bases de } \\
\text { dados de efeitos à saúde e ao } \\
\text { meio ambiente }\end{array}$ \\
\hline Propargito & $\begin{array}{l}\text { Risco consumidores, operadores, } \\
\text { trabalhadores e passantes. Risco } \\
\text { crônico mamíferos e vida aquática }\end{array}$ & $\begin{array}{c}\text { Irritante dérmico, danos } \\
\text { oculares. Suspeita carcinogênico. } \\
\text { Tóxico vida aquática (agudo e } \\
\text { crônico) }\end{array}$ & $\begin{array}{c}\text { Provável cancerígeno para seres } \\
\text { humanos }\end{array}$ \\
\hline Simazina & $\begin{array}{l}\text { Estudos insuficientes impacto } \\
\text { ambiental }\end{array}$ & $\begin{array}{l}\text { Suspeita carcinogênico. Tóxico } \\
\text { vida aquática (agudo e crônico) }\end{array}$ & $\begin{array}{c}\text { Desregulação endócrina para seres } \\
\text { humanos }\end{array}$ \\
\hline Tebutiurom & Sem informação & $\begin{array}{l}\text { Tóxico vida aquática } \\
\text { (agudo e crônico) }\end{array}$ & Sem informação \\
\hline Tiodicarbe & $\begin{array}{c}\text { Estudos insuficientes risco para } \\
\text { consumidores. Risco agudo dietético } \\
\text { para bebês (uvas) e adultos (vinhos); } \\
\text { Risco para aplicador. Contaminação } \\
\text { de águas subterrâneas (uso como } \\
\text { moluscicida) }\end{array}$ & Sem informação & $\begin{array}{c}\text { Provável cancerígeno para seres } \\
\text { humanos }\end{array}$ \\
\hline Trifluralina & $\begin{array}{c}\text { Estudos insuficientes impactos } \\
\text { ambientais. Tóxico sedimentos; } \\
\text { organismos aquáticos, } \\
\text { bioacumulação e persistência em } \\
\text { solo; transporte longas distâncias } \\
\text { pelo ar }\end{array}$ & $\begin{array}{l}\text { Sensibilização dérmica. Tóxico } \\
\text { vida aquática (agudo e crônico) }\end{array}$ & $\begin{array}{c}\text { Possível cancerígeno para seres } \\
\text { humanos }\end{array}$ \\
\hline
\end{tabular}

Nota: não foram incluídos no Quadro, apesar de proibidos na Comunidade Europeia: clorimuron-etílico, sulfentrazona, sulfluramida e triclopir-butotílico (pois não tinham nenhuma informação); diafentiurom e metano arseniato ácido monossodico (proibição segundo Regulamento $n^{\circ} 2.076 / 2002$ Comissão Europeia); imazetapir e novalurom (não aprovação segundo 2001/861/Comissão Europeia) 2004/129/Comissão Europeia e 2012/187/Comissão Europeia, 2009/579/Comissão Europeia).

do na maior demanda de aplicação dessas substâncias e, consequentemente, em maiores danos aos ecossistemas 18 .

Considerando os ingredientes ativos de agrotóxicos com dados de comercialização no Brasil, para 41 deles, incluindo os agrotóxicos glifosato, 2,4-D, acefato e atrazina, já havia registros de autorização para uso no país, em 1985, por meio da Portaria no 10 do Sistema Nacional de Vigilância em Saúde, do Ministério da Saúde 19. Outros 34 ingredientes ativos de agrotóxicos, dentre os 79 listados no relatório de comercialização de 2017, foram incluídos na Resolução no 165, de 29 de agosto de 2003 da Anvisa 20 .

Ainda sobre a diferença entre o Brasil e outros países e blocos econômicos analisados, na Comunidade Europeia, a malationa teve seu uso restrito para ambientes fechados em virtude dos graves efeitos agudos e crônicos para pássaros 21, mas é amplamente utilizada no território brasileiro por dispersão a Ultra Baixo Volume (popularmente conhecido como fumacê) para o controle de vetores, em ações de saúde pública. Agravando esse cenário, no Brasil, foi autorizada, segundo a Lei Federal no 13.301/2016 22, a aplicação, por aeronaves agrícolas, de inseticidas como a malationa em áreas densamente habitadas, mesmo com alerta de especialistas sobre a ineficácia e insegurança do método 23.

Os achados do presente estudo reiteram os prejuízos decorrentes das contaminações ampliadas, evidenciados em pesquisas nacionais 6, incluindo a presença de agrotóxicos em alimentos. Dados do Programa de Análise de Resíduos de Agrotóxicos em Alimentos (PARA), da Anvisa, mostram que, dentre os 20 ingredientes ativos de agrotóxicos mais encontrados nos alimentos pesquisados, sete representam 40\% do total de detecções e encontram-se proibidos em pelo menos três países da 
OCDE. Misturas de agrotóxicos também são frequentes, pois 35\% das amostras de alimentos pesquisadas continham de dois até 21 resíduos 24 .

Estudos recentes mostram a contaminação de rios, solo, flora e fauna, com produtos altamente danosos à vida e não permitidos em outros países, a exemplo do endossulfam (proibido no Brasil em 2013), da cipermetrina e da ametrina 25,26, esta última com potencial toxicidade para a vida aquática (Quadro 2).

A existência de danos ao meio ambiente e evidências indicativas de efeitos graves e potencialmente irreversíveis para seres humanos, como desregulação endócrina e carcinogenicidade, deveriam ser suficientes para a adoção de medidas precaucionárias, previstas na legislação brasileira. A importância deste estudo é reforçada pela recente aprovação da RDC no 294, de 29 de julho de 2019, que dispõe sobre os critérios para avaliação e classificação toxicológica sem indicar os estudos toxicológicos obrigatórios para os procedimentos de registro e reavaliação 27.

No Brasil, a pressão dos setores econômicos sobre os legisladores busca flexibilizar a Lei no 7.802/1989, que disciplina o registro, avaliação e uso de agrotóxicos no país. Dentre as mudanças propostas, está a retirada dos critérios de proibição de registro para agentes potencialmente carcinogênicos, tóxicos para o sistema reprodutivo, desreguladores endócrinos e teratogênicos, que atualmente são semelhantes aos critérios adotados na Europa. Com as mudanças, o uso de substâncias associadas a esses efeitos pode ser permitido mediante a avaliação de risco. Na Europa, também existe pressão sobre essa previsão, mas estudos têm mostrado que as supostas perdas econômicas não seriam superiores aos custos com saúde, perda de qualidade de vida individual, óbitos, redução de produtividade em decorrência do absenteísmo, entre outros 28.

Além de efeitos diversos, a desregulação endócrina tem indicação de proibição na Comunidade Europeia 29. No entanto, esse dispositivo encontra resistência para ser implementado de maneira plena, em decorrência das controvérsias e dúvidas produzidas pelos setores econômicos para definir os critérios necessários para essa classificação, estratégias comuns no que se refere à regulação e ao uso de substâncias tóxicas 30 .

A legislação europeia também prevê a definição dos agrotóxicos candidatos para substituição, que podem ter sua autorização de uso cancelada ${ }^{10}$. Para a inclusão na lista, os ingredientes ativos de agrotóxicos devem atender a pelo menos um dos seguintes critérios: (a) valores de ingestão diária aceitável (IDA), dose de referência aguda (DRfA) ou nível de exposição ocupacional aceitável (AOEL) menores que a maior parte das substâncias aprovadas na mesma categoria; (b) inclusão de dois critérios dentre persistência, bioacumulação ou toxicidade; (c) associação a efeitos considerados críticos (por exemplo, neurotoxicidade ou imunotoxicidade) em contextos onde medidas de controle de exposição não são eficazes, como o potencial de contaminação de águas subterrâneas, o uso de equipamentos de proteção individual (EPI) ou longas distâncias de aplicação; (d) grande proporção de isômeros não ativos; (e) classificação como carcinógeno, tóxico para o sistema reprodutivo ou desregulador endócrino, mas que não tenha sido proibido por razões estabelecidas em normas. Nessa lista, composta por 77 ingredientes ativos de agrotóxicos, constam 52 autorizados no Brasil, incluindo carbendazim, epoxiconazol, clorpirifós e linurom que, juntamente com tiofanato metilico, procimidona e clorotalonil, estão programados para serem reavaliados pela Anvisa com base na RDC no 221/2018 31 .

Em 2002, no Brasil, foi iniciada a revisão de registro para 18 ingredientes ativos de agrotóxicos devido a efeitos sobre a saúde humana. Os ingredientes ativos de agrotóxicos monocrotofos, pentaclorofeno e lindano foram proibidos em 2006; cihexatina, em 2009, e endossulfam, triclorfom, em 2010; metamidofós, em 2011; parationa metílica e forato, em 2015; procloraz, em 2016; e carbofurano, em 2017. O procloraz está autorizado em 77\% dos países estudados; o forato, em 31\%; carbofurano, endosulfan e pentaclorofenol, em 23\%; monocrotofos e cihexatina, em 15\%; metamidofós e parationa metílica, em 8\%; e lindano em nenhum país estudado. Tal achado demonstra que essas proibições adotadas pelo Brasil se alinham às dos demais países.

O paraquate, no ano de 2017, foi indicado para proibição, mas tem permissão de uso no país até 22 de setembro de 2020. Os registros do acefato, fosmete, lactofem e 2,4-D foram mantidos, e até maio de 2020 estavam inconclusos os processos de reavaliação toxicológica do glifosato e abamectina. A título de comparação, somente no ano de 2014, a China proibiu 50 agrotóxicos, iniciou o processo de proibição de outros 30 e anunciou, para o ano de 2022, o banimento de outros 12 ingredientes ativos de agrotóxicos 12 . 
Para as reavaliações que não haviam sido concluídas 6 anos depois de iniciadas, foi determinado judicialmente um prazo para finalização a partir de Ação Civil Pública movida pelo Ministério Público Federal (ACP no 21371-49.2014.4.01.3400 - 7ạ Vara Federal - Distrito Federal), considerando a possibilidade de efeitos sobre populações expostas. No caso do tiram e do lactofen, cujas reavaliações iniciaram em 2008, o parecer técnico da Anvisa indicou a manutenção do registro, mesmo sem terem sido avaliados aspectos importantes da sua toxicidade: "devido ao pouco tempo concedido judicialmente, não foi possível analisar todos os estudos disponíveis” 32 (p. 29). No parecer de reavaliação tanto do tiram como do lactofem, os estudos de toxicocinética (metabolismo) e de toxicidade aguda, subcrônica e crônica não foram apresentados, apesar de cruciais para a avaliação do perigo, do risco e do cálculo de limites de segurança como a DRfA e a IDA ${ }^{33}$. Neste estudo, observou-se que o tiram consta como não autorizado no Japão, Noruega e Islândia, enquanto o lactofem, em quase todos os países estudados, com exceção dos Estados Unidos e China.

$\mathrm{O}$ acefato e o 2,4-D, que entraram em reavaliação toxicológica no Brasil mas tiveram o registro mantido, não estão autorizados em diversos países, conforme demonstrado na Tabela 2. Os demais produtos reavaliados que foram mantidos ou estão com processo ainda inconcluso não têm permissão nos seguintes países: (i) fosmete - Índia, Japão, Nova Zelândia, Suíça, Noruega e Islândia; (ii) lactofem - Austrália, Canadá, Chile, Índia, Israel, Japão, México, Nova Zelândia, Suíça, Turquia, Comunidade Europeia, Noruega e Islândia; (iii) 2,4-D - Noruega e Islândia; e (iv) tiram - Japão, Noruega e Islândia. Durante a realização deste estudo, o tiram foi indicado para proibição pela Comunidade Europeia por causa de seus efeitos agudos para trabalhadores e consumidores, danos para aves e mamíferos, informações incompletas para um dos metabólitos e formação de N,N-nitrosodimetilamida (NDMA) em água potável 34 .

Em 2012, o Ibama indicou a suspensão da dispersão de quatro inseticidas por aeronaves em decorrência dos danos às abelhas: imidacloprido, tiametoxam, clotianidina e fipronil. Essa decisão foi suspensa logo em seguida por razões econômicas 35. O órgão regulador europeu proibiu o fipronil em 2010, adotou restrições severas, em 2013, para o imidacloprido, tiametoxam e clotianidina 36 e, em maio de 2018, anunciou a proibição do uso desses três ativos em áreas abertas devido aos danos às abelhas 37 .

A redução dos impactos dos agrotóxicos sobre a saúde humana e o meio ambiente é apontada, na Europa, por meio de medidas como as da Diretiva no 128/2009 38, voltada à promoção do manejo integrado de pragas e ao emprego de métodos sem a utilização de substâncias químicas, além de outras abordagens sustentáveis. Diretrizes de organizações como a FAO, Organização Pan-Americana da Saúde (OPAS) e OMS também orientam sobre a importância de fomentar outros modelos de agricultura, seja reduzindo o uso de agrotóxicos, seja até mesmo transitando para modos de produção orgânica e agroecológica 39. No Brasil, iniciativas governamentais, como a Política Nacional de Agroecologia e Produção Orgânica, instituída pelo Decreto no 7.794, de agosto de 2012, fomentaram a elaboração de um Programa Nacional de Redução de Agrotóxicos, nunca implementado 40, mas que tramita no Congresso Nacional via Projeto de Lei (PL) no 6.670/2016, que pretende instituí-lo como uma política pública.

Uma das limitações deste estudo foi a dificuldade de comparar os volumes de ingredientes ativos de agrotóxicos comercializados no Brasil e na Europa, uma vez que, nesta base, os dados são apresentados por grupos, de acordo com indicação de uso e grupo químico 41. Outra questão digna de nota foi a dificuldade de acessar as informações relacionadas à autorização de agrotóxicos nas bases oficiais dos Estados Unidos e China. Portanto, as informações sobre o registro nos Estados Unidos devem ser olhadas com reserva. As informações sobre registro na China foram obtidas de documento da FAO publicado em 2015 e podem ter sido atualizadas nesse período. Também não foi possível identificar as razões para a não autorização dos ingredientes ativos de agrotóxicos, que em geral não são apresentadas de forma clara e sistematizada pelas agências reguladoras.

Por essa razão, também foram pesquisadas, em bases oficiais, as classificações desses agrotóxicos quanto a efeitos crônicos graves. Na relação de monografias autorizadas da Anvisa, ingredientes ativos de agrotóxicos de uso agrícola com potencial de danos graves estavam incluídos na lista de candidatos para substituição, desreguladores endócrinos, prováveis ou possíveis carcinogênicos, cujos efeitos são indicativos de proibição segundo a legislação vigente. Deve-se ressaltar, no entanto, que a proibição de ingredientes ativos de agrotóxicos no Brasil também pode ocorrer para efeitos que não 
foram investigados neste estudo (como a teratogênese e a toxicidade reprodutiva), além de para outros igualmente graves (neurotoxicidade, imunotoxicidade etc.), a depender da relação dose e efeito aplicada ao uso pretendido. Aprofundar a investigação incluindo outros efeitos tóxicos pode aumentar o número de agrotóxicos autorizados no Brasil com potencial de danos graves à saúde.

Destacam-se três questões centrais a partir deste estudo. Primeiro, o Brasil, grande mercado consumidor mundial de agrotóxicos, utiliza produtos não permitidos em outros países, quase todos disponíveis há mais de quatro décadas no mercado nacional. Isso talvez não atraia a atenção das indústrias, que podem optar por lançar produtos mais modernos em locais que revisam questões ambientais, sanitárias e agronômicas de forma mais frequente.

Em segundo lugar, há necessidade de adoção de critérios mais protetivos no que se refere ao registro de agrotóxicos no país. Nesse sentido, o estudo mostra-se relevante ao destacar a importância da revisão de registro dos produtos não autorizados em pelo menos três países-membros da OCDE ou na Comunidade Europeia. Nos casos em que a desautorização de uso tivesse ocorrido por causa de danos para o meio ambiente ou para a saúde humana, o registro deveria ser imediatamente cancelado no Brasil.

Por fim, o estudo aponta a necessidade de maior transparência das agências reguladoras internacionais sobre as razões de autorização ou não dos ingredientes ativos de agrotóxicos, de modo a subsidiar ações de proteção e estimular o mercado global a desenvolver tecnologias menos prejudiciais e mais sustentáveis. Uma maior transparência é indispensável para subsidiar ações de proteção da biodiversidade e das populações humanas, em especial as mais vulneráveis, como comunidades e povos tradicionais, nos países periféricos. Também promoveria o desenvolvimento de tecnologias menos prejudiciais e modos de produção agrícola sustentáveis, como a Agroecologia, considerada pela FAO 39 como um caminho para atingir os Objetivos do Desenvolvimento Sustentável da Agenda 2030.

\section{Colaboradores}

K Friedrich, G. R. Silveira, J. C. Amazonas, A. M. Gurgel, V. E. S. Almeida e M. S. C. Mello contribuíram na concepção da pesquisa, coleta, análise e interpretação dos dados, redação, revisão e aprovação da versão final.

\section{Informações adicionais}

ORCID: Karen Friedrich (0000-0002-3661-6179); Gabriel Rodrigues da Silveira (0000-0003-04771585); Juliana Costa Amazonas (0000-0003-1804061X); Aline do Monte Gurgel (0000-0002-59813597); Vicente Eduardo Soares de Almeida (00000001-8201-3718); Marcia Sarpa de Campos Mello (0000-0001-8976-4653).

\section{Agradecimentos}

Ao Instituto Nacional de Câncer José Alencar Gomes da Silva (INCA) pela tradução da versão em inglês. 


\section{Referências}

1. Brasil. Lei no 7.802, de 11 de julho de 1989. Dispõe sobre a pesquisa, a experimentação, a produção, a embalagem e rotulagem, o transporte, o armazenamento, a comercialização, a propaganda comercial, a utilização, a importação, a exportação, o destino final dos resíduos e embalagens, o registro, a classificação, o controle, a inspeção e a fiscalização de agrotóxicos, seus componentes e afins, e dá outras providências Diário Oficial da União 1989; 12 jul.

2. Brasil. Decreto no 4.074 , de 4 de janeiro de 2002. Regulamenta a Lei no 7.802 , de 11 de julho de 1989, que dispõe sobre a pesquisa, a experimentação, a produção, a embalagem e rotulagem, o transporte, o armazenamento, a comercialização, a propaganda comercial, a utilização, a importação, a exportação, o destino final dos resíduos e embalagens, o registro, a classificação, o controle, a inspeção e a fiscalização de agrotóxicos, seus componentes e afins, e dá outras providências. Diário Oficial da União 2002; 8 jan.

3. Ministério da Saúde; Agência Nacional de Vigilância Sanitária. RDC no 221, de 28 de março de 2018. Diário Oficial da União 2018; 29 mar.

4. Franco CR, Pelaez V. Constructing the political agenda of control over pesticides in Brazil. Ambiente \& Sociedade 2016; 1:215-32.

5. Câmara dos Deputados. Projeto de Lei no $6.299 / 2002$. Altera os arts 3o e 9o da Lei no 7.802 , de 11 de julho de 1989 , que dispõe sobre a pesquisa, a experimentação, a produção, a embalagem e rotulagem, o transporte, o armazenamento, a comercialização, a propaganda comercial, a utilização, a importação, a exportação, o destino final dos resíduos e embalagens, o registro, a classificação, o controle, a inspeção e a fiscalização de agrotóxicos, seus componentes e afins, e dá outras providências. https://www.camara.leg.br/proposicoesWeb/ fichadetramitacao?idProposicao $=46249$ (acessado em 04/Jun/2020).

6. Carneiro FF, Rigotto RM, Augusto LGS, Friedrich K, Burigo AC. Dossiê Abrasco: um alerta sobre os impactos dos agrotóxicos na saúde. Rio de Janeiro: Escola Politécnica em Saúde Joaquim Venâncio, Fundação Oswaldo Cruz/ São Paulo: Expressão Popular; 2015.

7. Porto MFS. O trágico Pacote do Veneno: lições para a sociedade e a Saúde Coletiva. Cad Saúde Pública 2018; 34:e00110118.

8. International Agency for Research on Cancer. Pentachlorophenol and some related compounds. (IARC Monographs on the Identification of Carcinogenic Hazards to Humans 2019; 117). https://publications.iarc.fr/BookAnd-Report-Series/Iarc-Monographs-OnThe-Identification-Of-Carcinogenic-HazardsTo-Humans/Pentachlorophenol-And-SomeRelated-Compounds-2019.(acessado em 11/ Jun/2020).
9. United States Environmental Protection Agency. Chemicals evaluated for carcinogenic potential annual cancer report. http://npic. orst.edu/chemicals_evaluated.pdf (acessado em 11/Jun/2020).

10. Directorate General for Health and Consumers, European Commission. Ad-hoc study to support the initial establishment of the list of candidates for substitution as required in $\mathrm{Ar}$ ticle 80 (7) of Regulation (EC) n 1107/2009. Final report. https://ec.europa.eu/food/sites/ food/files/plant/docs/pesticides_ppp_appproc_cfs_report-201307.pdf (acessado em 11/ Jun/2020).

11. European Commission. Which substances are of concern? https://ec.europa.eu/environment/chemicals/endocrine/strategy/substances_en.htm\#sub1 (acessado em 12/Jun/2020).

12. Food and Agriculture Organization of the United Nations. Progress in pesticide risk assessment and phasing-out of highly hazardous pesticides in Asia (2015). http://www.fao.org/3 /a-i4362e.pdf (acessado em 12/Jun/2020).

13. Convention Stockholm. All POPs listed in the Stockholm Convention. http://www. pops.int/TheConvention/ThePOPs/AllPOPs/ tabid/2509/Default.aspx (acessado em 12/ Jun/2020).

14. Bozzini E. Pesticide policy and politics in the European Union: regulatory assessment, implementation and enforcement. Cham: Palgrave Macmillan; 2017.

15. Paula AGO. O regime de regulação de riscos para o controle dos agrotóxicos no Brasil: comparação com os regimes da França e da Califórnia/EUA [Dissertação de Mestrado]. Brasília: Fundação Jorge Duprat Figueiredo de Segurança e Medicina do Trabalho; 2002.

16. European Parliament. Renewing the approval of the active substance glyphosate European. https://www.europarl.europa.eu/doceo/docu ment/TA-8-2017-0395_EN.pdf (acessado em 11/Jun/2020).

17. Abreu PHB, Alonzo HGA. O agricultor familiar e o uso (in)seguro de agrotóxicos no município de Lavras/MG. Rev Bras Saúde Ocup 2016; 41:e18.

18. Almeida VES, Friedrich K, Tygel AF, Melgarejo L, Carneiro FF. Use of genetically modified crops and pesticides in Brazil: growing hazards. Ciênc Saúde Colet 2017; 22:3333-9.

19. Ministério da Saúde. Portaria no 10/SNVS, de 8 de março de 1985. Diário Oficial da União 1985; 14 mar.

20. Ministério da Saúde. Resolução DC/ANVISA no 165 , de 29 de agosto de 2003. Publica o "Índice das monografias dos ingredientes ativos de agrotóxicos, domissanitários e preservantes de madeira”. Diário Oficial da União 2003; 2 set. 
21. European Commission. Final review report for the active substance malathion finalised in the Standing Committee on the Food Chain and Animal Health at its meeting on 27 November 2009 in view of the inclusion of malathion in Annex I of Directive 91/414/EEC. https:// ec.europa.eu/food/plant/pesticides/eu-pesti cides-database/active-substances/?event $=$ as. details\&as_id=273 (acessado em 27/Jun/2020).

22. Brasil. Lei no 13.301, de 27 de junho de 2016. Dispõe sobre a adoção de medidas de vigilância em saúde quando verificada situação de iminente perigo à saúde pública pela presença do mosquito transmissor do vírus da dengue, do vírus chikungunya e do vírus da zika; e altera a Lei no 6.437, de 20 de agosto de 1977. Diário Oficial da União 2016; 28 jun.

23. Nota contra pulverização aérea de inseticidas para controle de vetores. Abrasco 2016; 29 abr. https://www.abrasco.org.br/site/noticias/ saude-da-populacao/nota-contra-pulveriza cao-aerea-de-inseticidas-para-controle-devetores-de-doencas/17430/ (acessado em 27/ Jun/2020).

24. Agência Nacional de Vigilância Sanitária. Programa de Análise de Resíduos de Agrotóxicos em Alimentos. Relatório das amostras analisadas no período de 2017-2018. https://www. gov.br/anvisa/pt-br/assuntos/agrotoxicos/ programa-de-analise-de-residuos-em-alimen tos (acessado em 28/Jun/2020).

25. Pignati MT, Costa LS, Mendes RA, Lima MO, Pignati WA, Pezzuti CBJ. Levels of organochlorine pesticides in Amazon turtle (Podocnemis unifilis) in the Xingu River, Brazil. J Environ Sci Health B 2018; 53:810-6.

26. Guida YS, Meire RO, Torres JPM, Malm O. Air contamination by legacy and current-use pesticides in Brazilian mountains: an overview of national regulations by monitoring pollutant presence in pristine areas. Environ Pollut 2018; 242:19-30.

27. Ministério da Saúde; Agência Nacional de Vigilância Sanitária. Resolução da Diretoria Colegiada no 294, de 29 de julho de 2019. Dispõe sobre os critérios para avaliação e classificação toxicológica, priorização da análise e comparação da ação toxicológica de agrotóxicos, componentes, afins e preservativos de madeira, e dá outras providências. Diário Oficial da União 2019; 31 jul.

28. Policy Department Economic and Scientific Policy, European Parliament. The benefits of strict cut-off criteria on human health in relation to the proposal for a Regulation concerning plant protection products. https:// www.europarl.europa.eu/RegData/etudes/ etudes/join/2008/408559/IPOL-JOIN ET(2008)408559_EN.pdf (acessado em 03/ $\mathrm{Jul} / 2020)$.

29. União Europeia. Regulamento (CE) no 1.107/2009 do Parlamento Europeu e do Conselho de 21 de Outubro de 2009 relativo à colocação dos produtos fitofarmacêuticos no mercado e que revoga as Diretivas 79/117/ CEE e 91/414/CEE do Conselho. Jornal Oficial da União Europeia 2009; 24 nov.
30. Michaels D. Doubt is their product: how industry's assault on science threatens your health. New York: Oxford University Press; 2008.

31. Agência Nacional de Vigilância Sanitária; Ministério da Saúde. Nova metodologia define reavaliação de agrotóxicos. http://anti go.anvisa.gov.br/resultado-de-busca?p_p_ id $=101 \&$ p_p_lifecycle $=0 \&$ p_p_state $=$ maxi mized\&p_p_mode $=$ view\&p_p_col_id $=$ co lumn-1\&p_p_col_count=1\&_101_struts_ac tion $=\% 2$ Fasset_publisher\%2Fview_con tent\&_101_assetEntryId $=5610165 \& \_101 \_$ type $=$ content $\& \_101 \_$groupId $=219201 \& \_101 \_$ urlTitle $=$ nova-metodologia-define-reavalia cao-de-agrotoxicos\&inheritRedirect $=$ true (acessado em 03/Jul/2020).

32. Agência Nacional de Vigilância Sanitária. Parecer Técnico de Reavaliação no 05, de 2015/GGTOX/ANVISA. Parecer Técnico de Reavaliação no 06, de 2015/GGTOX/ Anvisa. Reavalia o ingrediente ativo Tiram em relação à mutagenicidade, toxicidade reprodutiva, desregulação endócrina e neurotoxidade. http://antigo.anvisa.gov.br/documents/10181/2858811/Anexo+1+-+Pa recer $+5+$ de+2015+-+Muta_tox_reproduti va__desr_endocrina_neurotoxicidade.pdf/ $57 \mathrm{~d} 073 \mathrm{df}-9007-4820-8$ fec- $2424943 \mathrm{c} 78 \mathrm{~d} 7$ (acessado em 03/Jul/2020).

33. Agência Nacional de Vigilância Sanitária. Reavalia o ingrediente ativo Lactofem com relação aos aspectos de mutagenicidade, carcinogenicidade e efeitos reprodutivos. http://antigo. anvisa.gov.br/documents/33880/2541537/Pa recer\%2BT\%25C3\%25A9cnico\%2Bde\%2BRea valia\%25C3\%25A7\%25C3\%25A3o\%2BLac tofem\%2B-\%2BCP.pdf/98f129e9-af254fbd-94c3-98694a56ece5 (acessado em 03/ $\mathrm{Jul} / 2020$ ).

34. European Commission. Non-legislative Acts. Commission Implementing Regulation (EU) 2018/1500 of 9 October 2018, concerning the non-renewal of approval of the active substance thiram, and prohibiting the use and sale of seeds treated with plant protection products containing thiram. Official Journal of the European Union 2018; (254).

35. Ministério da Agricultura Pecuária e Abastecimento. Ato no 1, de 2 de outubro de 2012. Dispõe sobre a aplicação aérea dos ingredientes ativos imidacloprido, clotianidina, fipronil e tiametoxam. Diário Oficial da União 2012; 3 out.

36. European Commission. Bee health: EU takes additional measures on pesticides to better protect Europe's bees. Brussels: European Commission; 2013.

37. European Commission. Neonicotinoids. https://ec.europa.eu/food/plant/pesticides/ approval_active_substances/approval_re newal/neonicotinoids_en (acessado em 03/ $\mathrm{Jul} / 2020)$ 
38. European Parliament. Directive 2009/128/EC of the European Parliament and the Council of 21 October 2009 establishing a framework for Community action to achieve the sustainable use of pesticides. Official Journal of the European Union 2009; (309).

39. Committee on World Food Security. High level panel of experts. Report on agroecological and other innovative approaches for sustainable agriculture and food systems than enhance food security and nutrition. Rome: Food and Agriculture Organization of the United Nations; 2019.
40. Comissão Nacional de Agroecologia e Produção Orgânica. Proposta do Programa Nacional de Redução de Agrotóxicos. https://www. icict.fiocruz.br/sites/www.icict.fiocruz.br/ files/pronara-programa-nacional-de-reducaode-agrotoxicos-aprovado-por-merito-na-cna po-em-agosto-de-2014.pdf (acessado em 03/ Jul/2020).

41. Eurostat. Pesticide sales statistics. https:// ec.europa.eu/eurostat/statistics-explained/in dex.php?title=Archive:Pesticide_sales_statis tics (acessado em 03/Jul/2020). 


\section{Abstract}

The Brazilian legislation does not provide for a periodic review of the registration of pesticides and, even nowadays, products banned in other countries are still used. Based on the pesticide active substances registered in the country, the present study investigated the international regulatory situation in the following member countries: Organization for Economic Co-operation and Development (OECD), European Community, and the BRICS (Brazil, Russia, India, China, and South Africa). Moreover, we sought to relate the main chronic effects to human health and the environment of the most commercialized pesticide active substances in Brazil in lists of classification of carcinogenic potential (US Environmental Protection Agency - USEPA and International Agency for Research on Cancer - IARC), endocrine disruption, and candidates for substitution, both from the European Community. A total of 399 pesticide active substances registered in Brazil for agricultural use were identified, excluding microbiological and biological control agents. Of these, the percentage of unauthorized pesticide active ingredients according to countries is as follows: $85.7 \%$ in Iceland; $84.7 \%$ in Norway; $54.5 \%$ in Switzerland; $52.6 \%$ in India; $45.6 \%$ in Turkey; $44.4 \%$ in Israel; 43.4\% in New Zealand; $42.4 \%$ in Japan; $41.5 \%$ in the European Community; 39.6\% in Canada; $38.6 \%$ in China; $35.8 \%$ in Chile; $31.6 \%$ in Mexico; $28.6 \%$ in Australia; and $25.6 \%$ in the United States. 120 pesticide active substances were related to damage to health and the environment. Considering the pesticide active substances for which commercialization data are available in the country, $67.2 \%$ of this volume is associated with at least one serious chronic damage assessed in this study. The results of the present study indicate the need for promoting transparency of international databases, regarding the motivations of the respective regulatory decisions and the Brazilian regulatory bodies to reevaluate the registration of obsolete products and to strengthen public policies related to the reduction of the use of pesticides.

Agrochemicals; Neoplasms; Risk Assessment

\section{Resumen}

La legislación brasileña no prevé una revisión periódica del registro de los pesticidas e incluso hoy se utilizan productos prohibidos en otros países. Partiendo de los ingredientes activos de pesticidas registrados en el pais, el presente estudio investigó la situación regulatoria internacional en los siguientes países-miembros: Organización para la Cooperación y Desarrollo Económico (OCDE), Comunidad Europea, y BRICS. También se buscó relacionar los principales efectos crónicos para la salud humana y en el medio ambiente de los ingredientes activos de pesticidas más comercializados en Brasil en listas de clasificación con potencial cancerígeno (Agencia de Protección Ambiental de Estados Unidos - USEPA e Agencia Internacional de Investigación sobre el Cáncer - IARC), desregulación endocrina y candidatos para sustitución, ambos de la Comunidad Europea. Se identificaron 399 ingredientes activos de pesticidas registrados en Brasil para uso agrícola, excluyéndose los microbiológicos y agentes biológicos de control. De estos, no tienen autorización en Islandia 85,7\%, Noruega 84,7\%, Suiza 54,5\%, India 52,6\%, Turquia 45,6\%, Israel 44,4\%, Nueva Zelanda 43,4\%, Japón 42,4\%, Comunidad Europea 41,5\%, Canadá $39,6 \%$, China 38,6\%, Chile 35, 8\%, México 31,6\%, Australia 28,6\% y Estados Unidos 25,6\%. 120 ingredientes activos de pesticidas estuvieron relacionados con daños en la salud y medioambiente. Considerando los ingredientes activos de pesticidas para los cuales están disponibles datos de comercialización en el país, un 67,2\% de este volumen está asociado a por lo menos una enfermedad crónica grave evaluada en ese estudio. Los resultados del presente estudio indican la necesidad de promover la transparencia de las bases de datos internacionales, en lo que respecta a las motivaciones de las respectivas decisiones regulatorias, con el fin de que los órganos reguladores brasileños reevalúen el registro de productos obsoletos, así como para fortalecer políticas públicas relacionadas con la reducción del uso de pesticidas.

Agroquímicos; Neoplasias; Medición de Riesgo
Recebido 30/Mar/2020

Versão final reapresentada em 18/Jun/2020

Aprovado em 31/Jul/2020 